\begin{tabular}{|c|c|}
\hline Title & Difference in seasonal variation of net precipitation between the A rctic and A ntarctic regions \\
\hline Author(s) & Oshima, Kazuhiro; Y amazaki, Koji \\
\hline Citation & $\begin{array}{l}\text { Geophysical Research Letters, 33(L18501) } \\
\text { https://doi.org/10.1029/2006GL L27389 }\end{array}$ \\
\hline Issue Date & $2006-09-22$ \\
\hline Doc URL & http:/hdl .handle.net/2115/14779 \\
\hline Rights & $\begin{array}{l}\text { A n edited version of this paper was published by A GU; } \\
\text { Copyright 2006, A merican Geophysical Union, GEOPHY SICA L RESEA RCH LETTERS, V OL. 33, L18501 }\end{array}$ \\
\hline Type & article (author version) \\
\hline File Information & GR33-18.pdf \\
\hline
\end{tabular}

Instructions for use 


\section{Difference in Seasonal Variation of Net Precipitation between the Arctic and Antarctic Regions}

Kazuhiro Oshima and Koji Yamazaki

Faculty of Environmental Earth Science, Hokkaido University, Sapporo,

Japan

K. Oshima, Faculty of Environmental Earth Science, Hokkaido University, Sapporo, 060-0810, Japan. (kaz@ees.hokudai.ac.jp) 
The difference in the climatological seasonal variation of the net precipitation (precipitation minus evaporation) between the Arctic and the Antarctic was evaluated using ECMWF reanalysis data. Evaluated for simplified polar caps (the regions poleward of $70^{\circ} \mathrm{N}$ and $67.5^{\circ} \mathrm{S}$ ), over the Arctic, the net precipitation is large in the boreal summer, while, over the Antarctic, it is large in the austral winter. The net precipitation depends strongly on the poleward transient moisture flux into the region, which is affected by both the meridional moisture gradient and eddy activity. Thus, the seasonal variation of the poleward transient moisture flux is determined by the relative amplitude of the moisture and eddy factors, that is, by the ratio of the amplitude of the seasonal variation to the annual mean. While both regions have similar relative amplitudes of the eddy factor, the moisture factor in the Arctic is much larger than in the Antarctic. The moisture factor explains the difference in the seasonal variation of the net precipitation. 


\section{Introduction}

The Arctic and Antarctic are regions of moisture flux convergence. In the Arctic, moisture transport plays an important role in producing fresh water resources. For example, Oshima and Yamazaki [2004] estimated that one-third of the fresh water that enters the Arctic Ocean comes from the atmosphere and two-thirds from river runoff. The net input of water from the atmosphere to the surface, also called net precipitation, is the difference between precipitation and evaporation, that is, $P-E$. Furthermore, moisture transport directly or indirectly affects the snow, sea ice, and ice sheet over both the Arctic and Antarctic regions and is, thus, related to climate change. Therefore, in polar regions, atmospheric moisture transport is a critical element for determining the water balance and the climate.

The distribution of the poleward moisture flux across $70^{\circ} \mathrm{N}$ was investigated by Serreze et al. [1995] and Serreze and Barry [2000], using rawinsonde data. These studies discussed the distribution of poleward moisture flux across $70^{\circ} \mathrm{N}$. It is equivalent to the discussion on the net precipitation, since the net precipitation over the region poleward of a given latitude is approximately corresponded to the zonal mean poleward moisture flux at that latitude for a long period of time, such as the annual mean. This poleward flux corresponds to net precipitation for the region poleward from $70^{\circ} \mathrm{N}$ (hereafter called the polar cap region). It is shown that the net precipitation is large during boreal summer over the Arctic. This is reasonable because the precipitable water during the warm season is much larger than during the cold season. Similar seasonal variation was shown by Bromwich 
et al. [2000] using objective analysis data, and Groves and Francis [2002] using satellite data.

On the other hand, over the Antarctic, Yamazaki [1992, 1994] found that net precipitation is large during the austral winter, that is, during the cold season. The author suggested that this was due to enhanced cyclone activity in winter. Bromwich et al. [1995] and Cullather et al. [1998] also noted the same seasonal variation. However, the mechanism of this seasonal variation has not yet been quantitatively explained.

In this paper, we sought to explain the difference in the seasonal variation of the net precipitation between the Arctic and Antarctic regions by decomposing the transient moisture flux into the contributions due to the moisture effect and eddy effect.

Section 2 describes the data and analysis methods. Section 3 presents an evaluation of the moisture and eddy activity effects for the seasonal variation of the net precipitation. Section 4 summarizes the main conclusions of this paper.

\section{Data and analysis methods}

The ECMWF (European Centre for Medium-range Weather Forecasts) 40-year ReAnalysis (ERA40) dataset is used in this study. The temporal resolution is fourth-daily (6-hourly), and the horizontal resolutions are $2.5^{\circ}$ in latitude and longitude. Bromwich and Fogt [2004] compared the ERA40, NCEP/NCAR (National Centers for Environmental Prediction and National Center for Atmospheric Research) and station observation data for the Southern Hemisphere and showed that the presatellite era data had many shortcomings. Therefore, only the ERA40 data from the last 23 years (1979-2001), which assimilated satellite data, was used. 
In this study, the moisture flux, $\langle q \mathbf{v}\rangle$, is defined as the vertical integral of moisture flux, $q \mathbf{v}$, where $q$ is the specific humidity, and $\mathbf{v}$ is the wind vector. The angle brackets indicate vertical integration. The monthly mean total moisture flux can be divided into the stationary flux and transient flux as follows:

$\langle\overline{q \mathbf{v}}\rangle=\langle\bar{q} \overline{\mathbf{v}}\rangle+\left\langle\overline{q^{\prime} \mathbf{v} \prime}\right\rangle$

where the overbars represent a time average, calculated using the monthly average in this study, and the primes represent the deviation from the monthly average. The total flux is calculated from the monthly mean of 6-hourly flux and the stationary flux is calculated from the monthly mean fields of wind, moisture and surface pressure. The transient flux is obtained by subtracting the stationary flux from the total flux. Net precipitation, $P-E$, is estimated by the atmospheric moisture budget equation $(\partial P W / \partial t=-\nabla \cdot\langle q \mathbf{v}\rangle+E-P$, where, $P W$ is precipitable water).

\section{Results}

\subsection{Dominance of transient moisture flux}

Figure 1 shows the climatological seasonal variations of the net precipitation, $P-E$, the moisture flux convergence and the transient moisture flux convergence in the polar regions. For the Antarctic, $67.5^{\circ} \mathrm{S}$ was chosen instead of $70^{\circ} \mathrm{S}$, since the $70^{\circ} \mathrm{S}$ line crosses the East Antarctic continent. The annual mean net precipitation is $188 \mathrm{~mm} /$ year over the northern polar cap region, and $165 \mathrm{~mm} /$ year over the southern polar cap region, respectively. The seasonal variations in net precipitation over the Arctic and Antarctic are inversely related. The net precipitation is very closely related to the moisture flux convergence, which can be simply evaluated only by the zonal mean meridional flux at the 
latitude surrounding polar cap. The differences between net precipitation and moisture flux convergence in spring and fall are related to changes in atmospheric water vapor storage. The total moisture flux convergence depends strongly on the poleward transient moisture flux (TMF) into the region, that is, $\langle\overline{q v}\rangle \approx\left\langle\overline{q^{\prime} v \prime}\right\rangle$. Therefore, the main difference between the Arctic and Antarctic regions in the seasonal variation of the net precipitation comes from the difference in the TMF.

\subsection{Parameterization of the transient moisture flux}

Since the TMF is moisture transport by transient eddies from the humid lower latitudes to the drier higher latitudes, the magnitude of the flux is related to a meridional gradient of moisture content and to eddy activity. We assumed that the TMF is approximated by a product of moisture gradient and eddy activity. Since atmospheric moisture is relatively abundant in the lower troposphere and the moisture flux peaks around 850hPa [e.g., Serreze et al., 1995, Slonaker and Van Woert, 1999], $850 \mathrm{hPa}$ was chosen as a representative level. Thus, the moisture factor was defined as a zonal mean meridional gradient of specific humidity, $[\partial \bar{q} / \partial y]$, at $850 \mathrm{hPa}$, and the eddy factor as a zonal mean standard deviation of the meridional wind, $\sqrt{\left[\overline{v \prime^{2}}\right]}$, at $850 \mathrm{hPa}$.

Figure 2 shows the scatter diagram of the TMF and the product of the two factors for both polar regions and for each month of the years that were studied. The magnitude of the TMF and the product of the magnitude of moisture factor and eddy factor have a strong correlation $(\mathrm{R}=0.78)$ for both regions and all months. Therefore, the relationship between TMF, $\left|\left[\left\langle\overline{q^{\prime} v^{\prime}}\right\rangle\right]\right|$, moisture factor, $|[\partial \bar{q} / \partial y]|$, and eddy factor, $\sqrt{\left[\overline{v^{2}}\right]}$ is expressed 
as follows:

$\left|\left[\left\langle\overline{q^{\prime} v^{\prime}}\right\rangle\right]\right| \approx 1.13\left|\left[\frac{\partial \bar{q}}{\partial y}\right]\right| \times \sqrt{\left[\overline{v^{2}}\right]}$

where the square brackets denote the zonal mean.

\subsection{Seasonal variation of the transient moisture flux}

Figure 3 shows the seasonal variation of the moisture factor (green line with crosses) and the eddy factor (blue line with crosses). For both polar regions, the moisture factors are strongest during the summer, and the eddy factors are strongest during the winter. Although the moisture factor in the Antarctic shows very little seasonal variation, that in summer is slightly stronger than that in winter. The seasonal variations of the moisture factor and the eddy factor can be fitted using cosine curves (lines with open circles). Sine curves that express spring-fall contrasts are not included because we focus on summerwinter constants. From equation 2, the relation of the cosine approximation can be expressed for the seasonal variation as follows:

$$
\begin{aligned}
|[\langle\overline{q \prime v \prime}\rangle]| & \approx 1.13\left|\left[\frac{\partial \bar{q}}{\partial y}\right]\right| \times \sqrt{\left[\overline{v^{2}}\right]} \\
& \approx\left(a_{0}-a_{1} \cos t\right)\left(b_{0}+b_{1} \cos t\right) \\
& =a_{0} b_{0}\left\{1-\frac{1}{2} \frac{a_{1} b_{1}}{a_{0} b_{0}}+\left(\frac{b_{1}}{b_{0}}-\frac{a_{1}}{a_{0}}\right) \cos t-\frac{1}{2} \frac{a_{1} b_{1}}{a_{0} b_{0}} \cos 2 t\right\}
\end{aligned}
$$

where, $a_{0}$ is the annual average value for the moisture factor, $|[\partial \bar{q} / \partial y]|, a_{1}$ is the amplitude of the seasonal variation of the moisture factor. Similarly, $b_{0}$ and $b_{1}$ are those for the eddy factor, $\sqrt{\left[\overline{v^{2}}\right]}$. All the coefficients $\left(a_{0}, a_{1}, b_{0}, b_{1}\right)$ are positive. The initial time, $t=0$, is set to January. $a_{1}$ and $b_{1}$ are determined from the coefficient of wave number one in the Fourier expansion. In both polar regions, the moisture factor has a peak in the summer, 
while the eddy factor has a peak in the winter. The sign of $\left(b_{1} / b_{0}-a_{1} / a_{0}\right)$ determines whether the peak of the TMF appears in summer or winter.

Table 1 shows the coefficients of each term. In the Arctic region, the relative amplitude of the moisture factor, $\left(a_{1} / a_{0}\right)$, is much lager than that of the eddy factor, $\left(b_{1} / b_{0}\right)$. Thus, $\left(b_{1} / b_{0}-a_{1} / a_{0}\right)$ has a large negative value of -0.61 , and the seasonal variation shows a summer maximum. On the other hand, in the Antarctic region, $\left(b_{1} / b_{0}-a_{1} / a_{0}\right)$ has a small positive value of +0.10 , and the seasonal variation of the TMF shows a winter maximum. In both the Arctic and Antarctic, the relative amplitudes of the eddy factor have similar values (0.16 and 0.17), while the moisture factor in the Arctic (0.77) is much larger than in the Antarctic (0.06).

The observed and approximated seasonal variations of the TMF, moisture factor, and eddy factor are shown in Figure 3 (a: Arctic, b: Antarctic). Although the agreement is not perfect, the difference in the seasonal variation of TMF, i.e., net precipitation, between the Arctic and Antarctic regions can be understood with this simple explanation. One month phase shift of the TMF in the Arctic and the semi-annual variation in the Antarctic are not well produced by this approximation. However, as far as the winter-to-summer variation is concerned, it is captured by this simple approximation.

\section{Summary and Discussion}

Using the ERA40 dataset, the difference in the climatological seasonal variation of the net precipitation between the Arctic and the Antarctic was evaluated.

For both the Arctic and Antarctic, the total column water vapor, $P W$, peaks in summer. As expected, over the Arctic, the net precipitation is large in the boreal summer. On the 
other hand, over the Antarctic, the net precipitation is large in the austral winter. In both polar regions, the transient moisture flux (TMF) greatly contributes to the net precipitation. The seasonal variation of the net precipitation over these regions is mainly explained by the effect of poleward TMF.

The poleward TMF in both regions can be parameterized as a product of the meridional moisture gradient, which is the moisture factor, and the standard deviation of meridional wind, which is the eddy factor, at $850 \mathrm{hPa}$. Seasonal variations in the poleward TMF are obtained from the seasonal variations of these factors. In general, the moisture effect peaks in the summer, while the eddy effect peaks in the winter. It can be shown that the seasonal variation in the TMF is determined by the relative amplitude (ratio of the seasonal variation to the mean) of the moisture and eddy factors. While the relative amplitude of the eddy factor in both polar regions is comparable, the relative amplitude of the moisture factor in the Arctic is much larger than in the Antarctic. Therefore, the relative amplitude of the moisture factor is a key parameter that explains the difference between the two polar regions. It should be noted that the Arctic is surrounded by land, while the Antarctic is surrounded by ocean. This contributes to the difference seen in the seasonal variation of the meridional temperature gradient and the relative amplitude of the moisture factor in the polar regions.

Note that the net precipitation over the Arctic Ocean also shows a summer maximum, but over the northern high latitude land areas it shows a summer minimum, due to the high evapotranspiration rates over the land [Serreze et al., 2003]. The large moisture contrast between the Arctic Ocean and the surrounding land regions enhances poleward 
transient moisture flux in summer, which contributes to the summer maximum in net precipitation over the Arctic Ocean. The poleward moisture fluxes from the Pacific and the Atlantic Oceans are also enhanced in summer, especially in the stationary components [Oshima, 2005]. Both fluxes from oceans and lands contribute to the summer maximum in net precipitation over the northern polar cap.

In this study, the seasonal variation of net precipitation is discussed in terms of transient moisture flux. But the contributions of other components have to be considered for more detailed study. In the Arctic, the maximum in net precipitation appears in August and is delayed for about one month from the peak of TMF convergence or total flux convergence. The reason of this delay is that the poleward moisture flux into the Arctic region is used to increase $P W$ over the region in the warming season (spring) and the decrease in $P W$ affects the net precipitation in the cooling season (fall). In the Antarctic, about one-third of the amplitude of net precipitation depends on the stationary flux convergence. The seasonal variation of stationary moisture flux convergence has an austral winter maximum. This is caused by the winter intensification and southern shift of the stationary low over the Ross Sea. Therefore, it is need to calculate the changing rate of $P W$ in the Arctic and the stationary flux convergence in the Antarctic for the quantitative estimation of monthly net precipitation.

Acknowledgments. ECMWF ERA-40 data used in this study have been provided by ECMWF. The GFD DENNOU Library was used for analysis. We thank two reviewers for valuable comments. 


\section{References}

Bromwich, D. H., and R. L. Fogt, 2004: Strong Trends in the Skill of the ERA-40 and NCEP-NCAR Reanalyses in the High and Midlatitudes of the Southern Hemisphere, 1958-2001. J. Clim., 17, 4603-4619.

Bromwich, D. H., F. M. Robasky, R. I. Cullather, and M. L. V. Woert, 1995: The Atmospheric Hydrologic Cycle over the Southern Ocean and Antarctica from Operational Numerical Analyses. Mon. Wea. Rev., 123, 3518-3538.

Bromwich, D. H., R. I. Cullather, and M. C. Serreze, 2000: Reanalyses Depictions of the Arctic Atmospheric Moisture Budget. in Lewis, E. ed., The Fresh Water Budget of the Arctic Ocean, Kluwer Academic Publishers, 163-196.

Cullather, R. I., D. H. Bromwich, and M. L. V. Woert, 1998: Spatial and Temporal Variability of Antarctic Precipitation from Atmospheric Methods. J. Clim., 11, 334367.

Groves, D. G., and J. A. Francis, 2002: Moisture budget of the Arctic atmosphere from TOVS satellite data. J. Geophys. Res., 107(D19), doi: 10.1029/2001JD001191.

Oshima, K., and K. Yamazaki, 2004: Seasonal Variation of Moisture Transport in Polar Regions and the Relation with Annular Modes. Polar Meteorology and Glaciology, 18, $30-53$.

Oshima, K., 2005: Seasonal Variation of the Atmospheric Hydrologic Cycle in Polar Regions and the Relation with Annular Modes. $\underline{P h D \text { thesis, }}$ Graduate School of Environmental Earth Science, Hokkaido University, 86 pp. 
Serreze, M. C., and R. G. Barry, 2000: Atmospheric components of the Arctic Ocean hydrologic budget assessed from rawinsonde data. in Lewis, E. ed., The Fresh Water



Serreze, M. C., R. G. Barry, and J. E. Walsh, 1995: Atmospheric Water Vapor Characteristics at $70^{\circ} \mathrm{N}$. J. Clim., 8, 719-731.

Serreze, M. C., D. H. Bromwich, M. P. Clark, A. J. Etringer, T. Zhang, and R. Lammers, 2003: Large-scale hydro-climatology of the terrestrial Arctic drainage system. J. Geophys. Res., 108(D2), doi: 10.1029/2001JD000919.

Slonaker, R. L., and M. L. Van. Woert, 1999: Atmospheric moisture transport across the Southern Ocean via satellite observations. J. Geophys. Res., 104(D8), 9229-9249.

Yamazaki, K., 1992: Moisture Budget in the Antarctic Atmosphere. Proc. NIPR Symp. Polar Meteorol. Glaciol., 6, 36-45.

Yamazaki, K., 1994: Moisture budget in the Antarctic atmosphere. in Jones, H. G., T. D. Davies, A. Ohmura, and E. M. Morris eds., Snow and Ice Covers: Interactions with the Atmosphere and Ecosystems, Vol. 223 of IAHS Publ., 61-67. 
Table 1. Coefficients of equation (3). $a_{0}$ is the annual average of the moisture factor, $|[\partial \bar{q} / \partial y]| . \quad a_{1}$ is its amplitude of the seasonal variation. $b_{0}$ is the annual average of the eddy factor, $\sqrt{\left[\overline{v^{2}}\right]} \cdot a_{1} / a_{0}$ and $b_{1} / b_{0}$ are the relative amplitudes of the moisture factor and the eddy factor.

\begin{tabular}{c||c|c}
\hline & Arctic, $70^{\circ} \mathrm{N}$ & Antarctic, $67.5^{\circ} \mathrm{S}$ \\
\hline$a_{0}$ & 0.89 & 1.11 \\
\hline$a_{1}$ & 0.68 & 0.07 \\
\hline$b_{0}$ & 5.66 & 6.39 \\
\hline$b_{1}$ & 0.91 & 1.07 \\
\hline$a_{0} * b_{0}$ & 5.01 & 7.07 \\
\hline$a_{1} / a_{0}$ & 0.77 & 0.06 \\
\hline$b_{1} / b_{0}$ & 0.16 & 0.17 \\
\hline $\mathbf{b}_{\mathbf{1}} / \mathbf{b}_{\mathbf{0}}-\mathbf{a}_{\mathbf{1}} / \mathbf{a}_{\mathbf{0}}$ & $\mathbf{- 0 . 6 1}$ & $\mathbf{0 . 1 0}$ \\
\hline$\left(a_{1} * b_{1}\right) /\left(a_{0} * b_{0}\right)$ & 0.12 & 0.01 \\
\hline
\end{tabular}




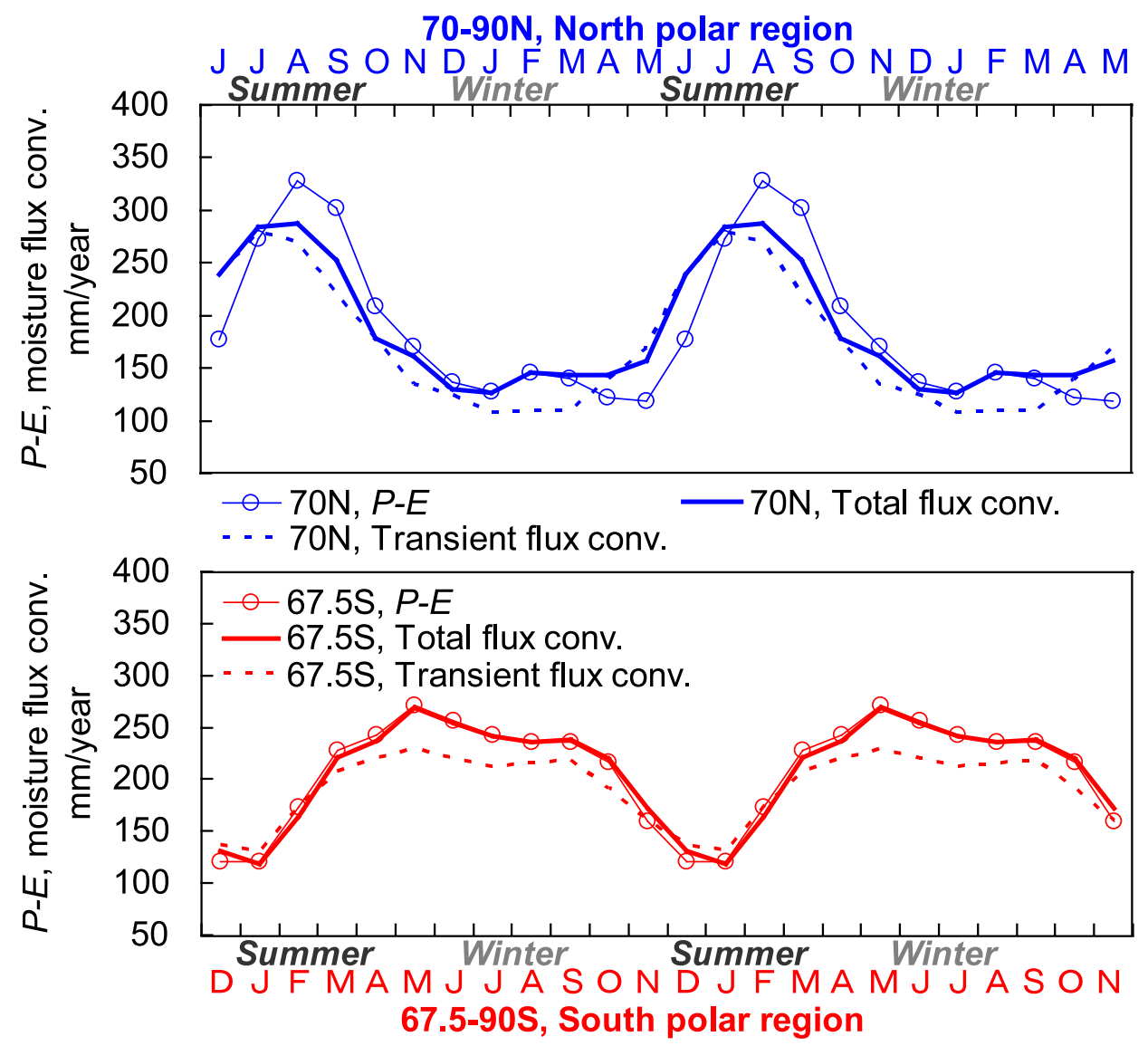

Figure 1. Seasonal variation of the net precipitation, $P-E$, over the polar cap regions (the regions poleward of $70^{\circ} \mathrm{N}$ and $67.5^{\circ} \mathrm{S}$ ). The upper figure shows the net precipitation over the Arctic, while the lower figure shows the net precipitation over the Antarctic. Thin solid lines with open circles indicate the net precipitations over the polar cap regions. Thick lines denote the total moisture flux convergences, while the dashed lines denote the transient moisture flux convergences. The abscissas represent the month. Note that the abscissas have been shifted by 6 months between the two figures. Two annual cycles are repeated. 


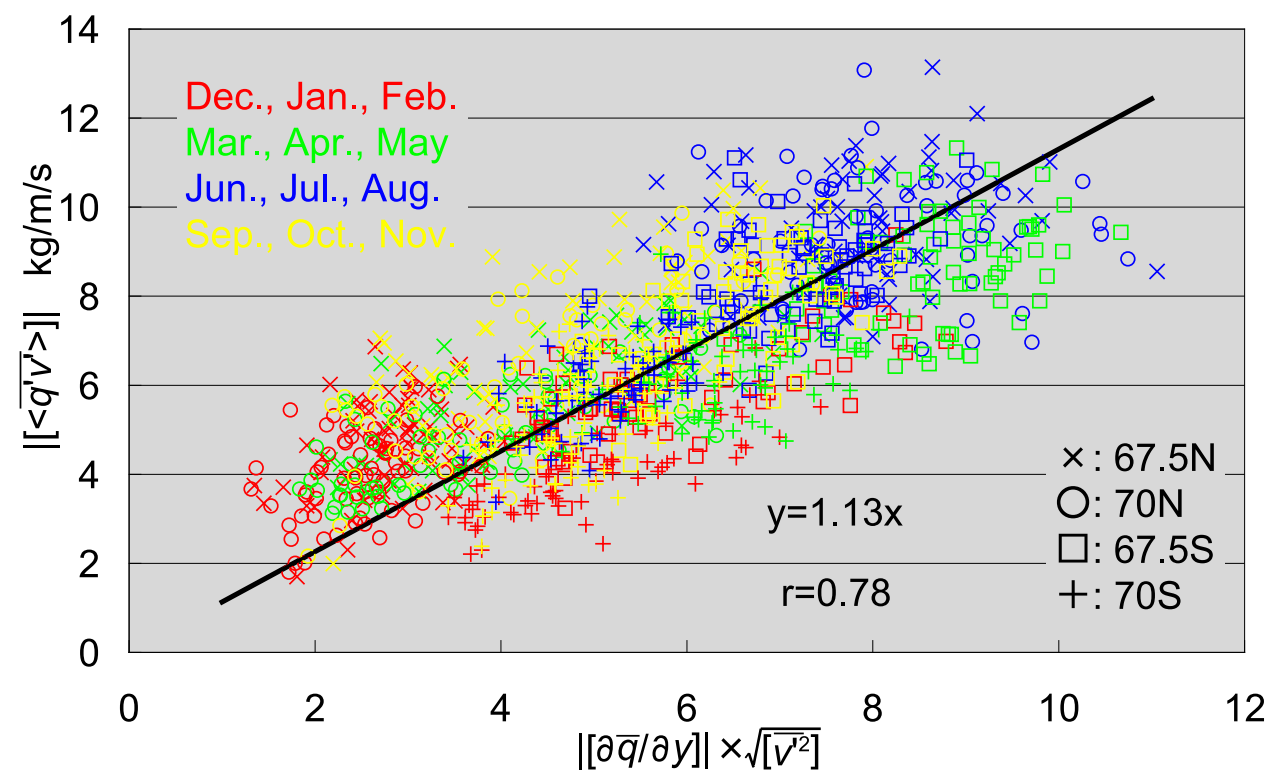

Figure 2. Scatter diagram of the TMF, $|[\langle\overline{q / v /}\rangle]|$, as a function of the product of the moisture factor, $|[\partial \bar{q} / \partial y]|$, and the eddy factor, $\sqrt{\left[\overline{v^{\prime 2}}\right]}$, for both polar regions and all of the months. The colors and marks indicate the 4 seasons and the latitudes, which are denoted in the figure. The black solid line is the linear regression. 

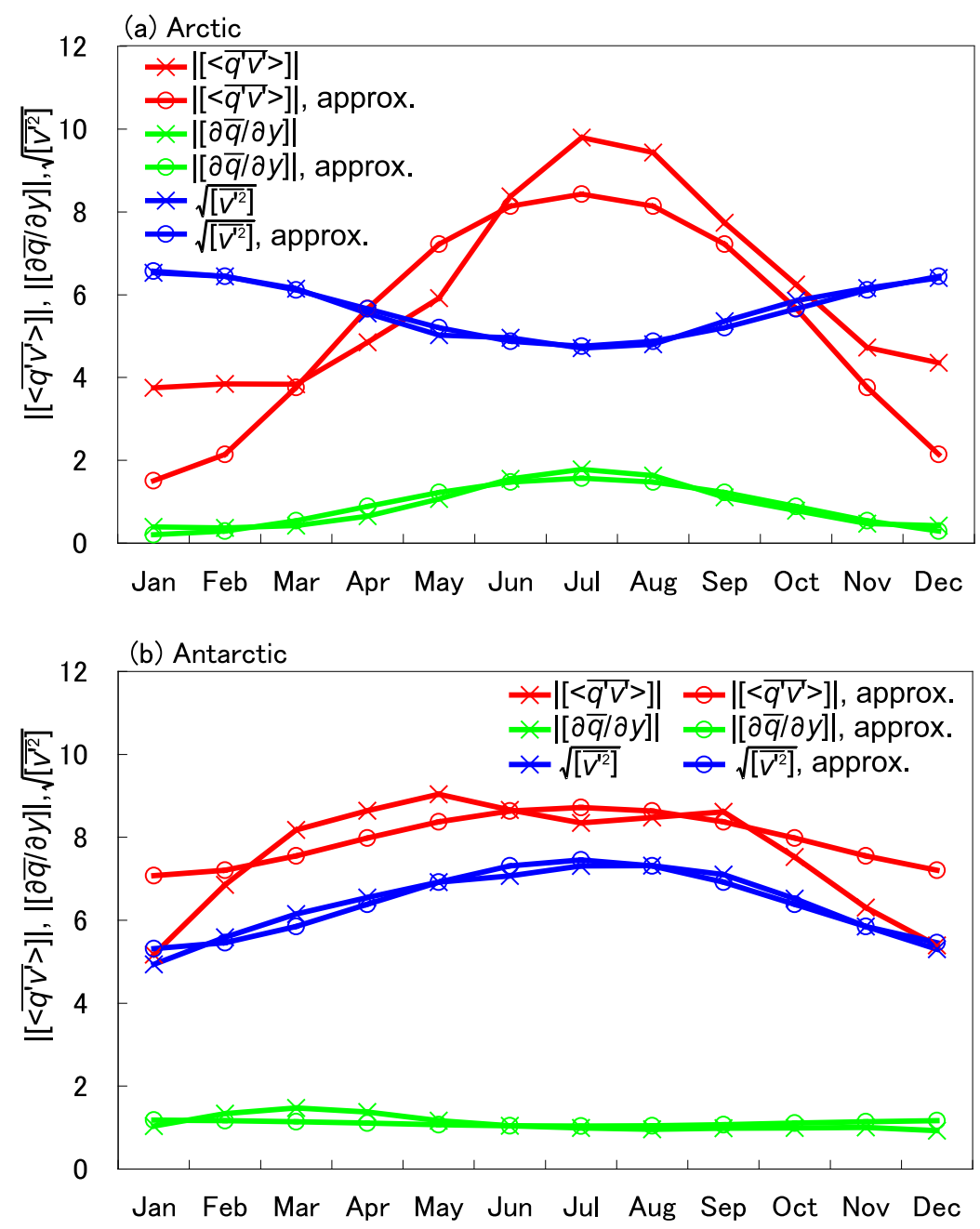

Figure 3. Seasonal variations of the zonal mean transient moisture flux (TMF), (a) at $70^{\circ} \mathrm{N}$ and, (b) at $67.5^{\circ} \mathrm{S}$, estimated from the harmonic approximation. The red line with crosses and with open circles indicate the observed and approximated values of TMF, $\left|\left[\left\langle\overline{q^{\prime} v^{\prime}}\right\rangle\right]\right|$. Same as $\left|\left[\left\langle\overline{q^{\prime} v^{\prime}}\right\rangle\right]\right|$, the green and blue lines show moisture factor, $|[\partial \bar{q} / \partial y]|$ and eddy factor, $\sqrt{\left[\overline{v^{2}}\right]}$, respectively. 